\title{
Desempenho de novilhos Nelore alimentados com casca de soja ou farelo de gérmen de milho em substituição parcial ao milho moído ${ }^{1}$
}

\author{
Jane Maria Bertocco Ezequiel ${ }^{2}$, Octávio Guilherme da Cruz e Silva ${ }^{3}$, Rosemary Laís Galati ${ }^{4}$, \\ Pedro Henrique Watanabe ${ }^{5}$, Bruno Biagioli ${ }^{3}$, Cristian Faturi $^{5}$
}

\footnotetext{
1 Projeto financiado pela FAPESP e Caramuru Alimentos Ltda.

2 Departamento de Zootecnia na FCAV/Unesp.

${ }^{3}$ Zootecnistas formados pela FCAV/Unesp.

4 Zootecnista, Doutora em Zootecnia pela FCAV/Unesp.

${ }^{5}$ Pós-Graduação em Zootecnia - FCAV/Unesp.
}

RESUMO - Objetivou-se neste trabalho estudar a substituição parcial (70\%) do milho moído pela casca de soja ou pelo farelo de gérmen de milho em dietas contendo farelo de girassol e uréia (fontes nitrogenadas) e silagem de milho (volumoso) para novilhos Nelore em confinamento. Avaliaram-se o consumo, o ganho de peso, a conversão alimentar e o rendimento de carcaça de 21 animais (25 meses de idade e peso inicial de $343 \mathrm{~kg}$ ) alimentados com as dietas-teste, fornecidas na proporção 60:40 volumoso:concentrado. O período de avaliação do consumo e do ganho de peso foi de 97 dias. Os consumos de MS (10,78; 9,73 e 10,62 kg/dia), PB (1,40; 1,22 e 1,41 kg/dia) e FDN (3,41; 3,89 e 3,60 kg/dia) não foram influenciados pelas dietas com milho moído, casca de soja e farelo de gérmen de milho, respectivamente. O consumo de FDA $(0,56$; 0,71 e $0,55 \%$ PV) apresentou efeito significativo, observando-se maior valor quando a casca de soja substituiu $70 \%$ do milho moído. O ganho de peso não foi influenciado pelas dietas, registrando-se valores de 1,35; 1,29 e 1,32 kg/dia para as dietas contendo milho moído, casca de soja e farelo de gérmen de milho, respectivamente. Não houve efeito, também, sobre a conversão alimentar (7,88 kg de MS ingerida $/ \mathrm{kg}$ ganho), a eficiência alimentar $(0,12 \mathrm{~kg}$ ganho/kg MS ingerida) e o rendimento de carcaça (54,52\%). A substituição parcial do milho moído pela casca de soja e pelo farelo de gérmen de milho em dietas para novilhos em confinamento não afeta o desempenho e o rendimento de carcaça.

Palavras-chave: bovinos de corte, consumo, conversão alimentar, ganho em peso, rendimento de carcaça

\section{Effects of partial replacement of ground corn with soybean hulls or corn germ meal on production of Nellore steers}

\begin{abstract}
The objective of this trial was to study the partial replacement of ground corn with soybean hulls or corn germ meal in diets containing sunflower meal and urea as nitrogen sources and corn silage as forage for confined Nellore steers. Twenty-one steers averaging 25 months of age and $343 \mathrm{~kg}$ of initial body weight were assigned to diets containing a forage:concentrate ratio of 60:40. The period for measurements of intake and weight gain lasted 97 days. No significant differences were observed for intakes of dry matter $(10.78,9.73$, and $10.62 \mathrm{~kg} / \mathrm{day})$, crude protein $(1.40,1.22$, and $1.41 \mathrm{~kg} / \mathrm{day})$, and neutral detergent fiber $(3.41,3.89$, and $3.60 \mathrm{~kg} / \mathrm{day})$, respectively, for diets containing ground corn, soybean hulls, and corn germ meal. However, intake of acid detergent fiber was highest $(0.71 \% \mathrm{BW})$ for steers consuming the diet that soybean hulls replaced $70 \%$ of ground corn. Weight gain did not differ averaging $1.35,1.29$, and $1.32 \mathrm{~kg}$ /day feeding ground corn, soybean seed hulls, and corn germ meal, respectively. In addition, no significant differences were observed for feed conversion $(7.88 \mathrm{~kg}$ of DMI $/ \mathrm{kg}$ of weight gain), feed efficiency ( 0.12 weight gain $/ \mathrm{kg}$ of DMI), and carcass dressing (54.52\%) across treatments. It can be concluded that soybean hulls and corn germ meal can partially replace ground corn in diets for confined steers because both production and carcass dressing were maintained.
\end{abstract}

Key Words: beef cattle, carcass dressing, feed conversion, intake, weight gain

\section{Introdução}

O processamento primário ou industrial de alimentos destinados à alimentação animal e humana nos últimos anos foi responsável por uma elevada produção de resíduos, que, em sua maioria, possuem potencial nutricional principalmente para a formulação de dietas para bovinos. Esses resíduos têm recebido, no entanto, maior atenção quanto ao controle de qualidade, passando à categoria de co-produtos, que apresenta elevado potencial para redução dos custos com alimentação, sobretudo de bovinos confinados. 
O grão de milho é o ingrediente mais comum nas dietas, mas, quando utilizado em grandes quantidades, pode provocar efeito associativo negativo sobre a digestão da fibra (Hoover, 1986), ocasionando a introdução de agentes tamponantes que evitem a queda brusca do $\mathrm{pH}$ ruminal. A utilização de ingredientes ricos em fibra e com potencial energético pode ser uma alternativa viável para se evitar ou minimizar esse efeito.

Entre os co-produtos disponíveis, encontram-se a casca de soja e o farelo de gérmen de milho, potenciais fontes substitutivas parciais ou totais do milho em grão em dietas para bovinos (Fisher \& Mühlbach, 1999; Galati et al., 2003; Ezequiel et al., 2004; Mendes et al., 2005). Como substituto ao farelo de soja, tem-se o farelo de girassol, ótima fonte protéica na alimentação de bovinos em confinamento (Galati, 2004; Mendes et al., 2005).

A casca de soja se caracteriza por seu teor em fibra potencialmente digestível, que lhe confere a capacidade de ser utilizada como fonte volumosa ou concentrada, possibilitando desempenho semelhante ao obtido com milho (Silva et al., 2002; Ezequiel et al., 2004; Mendes et al., 2005). $\mathrm{O}$ farelo de gérmen de milho, co-produto do milho, possui teor de fibra (26,4 e 8,8\% para FDN e FDA, respectivamente) superior ao do milho ( 9,4 e 3,2\% de FDN e FDA). O valor nutritivo desse co-produto em dietas para bovinos ainda é pouco conhecido, contudo, pesquisas recentes têm comprovado seu potencial como substituto parcial ao milho, verificando-se, inclusive, tendência em proporcionar maior espessura de gordura subcutânea, o que, do ponto de vista de qualidade da carne, pode ser um diferencial no mercado consumidor (Ezequiel et al., 2004; Galati, 2004; Mendes et al., 2005).

Neste trabalho objetivou-se avaliar o consumo, o ganho médio diário, a conversão alimentar e o rendimento de carcaça de novilhos Nelore alimentados com dietas contendo casca de soja ou farelo de gérmen de milho em substituição parcial ao milho moído.

\section{Material e Métodos}

O experimento foi conduzido no Setor de Confinamento do Departamento de Zootecnia da Faculdade de Ciências Agrárias e Veterinárias/Unesp, Campus de Jaboticabal.

Foram utilizados 21 novilhos da raça Nelore criados em pastagens, com aproximadamente 25 meses de idade e peso médio inicial de $343 \mathrm{~kg}$. Antes do início do experimento, os animais foram tratados com Ivermectina, para controle de endo e ectopasitos. Os animais foram distribuídos aleatoriamente na instalação, ficando alojados em baias individuais $\left(14 \mathrm{~m}^{2}\right)$, cimentadas e parcialmente cobertas, dotadas de cochos de madeira, individuais, e cochos para água, dispostos a cada dois animais.

Os concentrados continham como fontes energéticas casca de soja e farelo de gérmen de milho peletizados em substituição parcial (70\%) ao milho moído e, como fontes nitrogenadas, farelo de girassol peletizado e uréia pecuária. Como volumoso, utilizou-se silagem de milho. Durante o período de adaptação e ajuste do consumo alimentar (21

Tabela 1 - Composição bromatológica dos ingredientes utilizados nas dietas

Table 1 - Chemical composition of diet ingredients

\begin{tabular}{|c|c|c|c|c|c|c|c|c|c|}
\hline \multirow{4}{*}{$\begin{array}{l}\text { Ingrediente } \\
\text { Ingredient }\end{array}$} & \multicolumn{9}{|c|}{$\begin{array}{c}\text { Componente } \\
\text { Component }\end{array}$} \\
\hline & MS & MO & $\mathrm{PB}$ & $\mathrm{EE}$ & \multirow{3}{*}{$\begin{array}{l}\mathrm{FDN} \\
N D F \\
\% \mathrm{MS} \\
D M \%\end{array}$} & FDA & Amido & $\mathrm{CNF}^{2}$ & \multirow{3}{*}{$\begin{array}{c}\mathrm{EM}^{3} \\
M E^{2} \\
\text { Mcal } / \mathrm{kg} \mathrm{MS} \\
\text { Mcal.kg DM } \\
\end{array}$} \\
\hline & $D M$ & $O M$ & $C P$ & $E E$ & & $A D F$ & Starch & $N F C^{l}$ & \\
\hline & $\%$ & & & & & & & & \\
\hline $\begin{array}{l}\text { Silagem de milho } \\
\text { Corn silage }\end{array}$ & 44,4 & 96,7 & 7,4 & 2,3 & 36,2 & 19,2 & 19,7 & 50,8 & 2,2 \\
\hline $\begin{array}{l}\text { Milho moído } \\
\text { Ground corn }\end{array}$ & 87,8 & 98,4 & 11,8 & 4,3 & 9,4 & 3,2 & 65,6 & 72,9 & 3,2 \\
\hline $\begin{array}{l}\text { Casca de soja } \\
\text { Soybean hulls }\end{array}$ & 90,5 & 94,9 & 10,6 & 1,7 & 72,5 & 56,9 & 6,5 & 10,1 & 2,8 \\
\hline $\begin{array}{l}\text { Farelo de gérmen de milho } \\
\text { Corn germ meal }\end{array}$ & 89,1 & 95,8 & 13,0 & 1,6 & 26,4 & 8,8 & 37,2 & 54,8 & 3,0 \\
\hline $\begin{array}{l}\text { Farelo de girassol } \\
\text { Sunflower meal }\end{array}$ & 90,3 & 95,4 & 31,0 & 0,8 & 49,7 & 40,0 & 4,7 & 13,9 & 2,4 \\
\hline $\begin{array}{l}\text { Uréia } \\
\text { Urea }\end{array}$ & 98,0 & - & 250,0 & - & - & - & - & - & - \\
\hline
\end{tabular}

${ }_{1}^{1}$ Carboidratos não-fibrosos (CNF) $=$ MO - PB - EE - FDN ${ }_{C P B}$ (Sniffen et al., 1992)

1 Nonfiber carbohydrates $(N F C)=O M-C P-E E-N D F_{c C P}$

2 Energia metabolizável (EM) estimada a partir dos nutrientes digestíveis totais (NDT), segundo Sniffen et al. (1992), utilizando-se os dados de digestibilidade obtidos por Watanabe (2004).

2 Metabolizable energy (ME) estimated by total digestible nutrients (TDN) according to Sniffen et al. (1992) using the digestibility values obtained by Watanabe (2004). 
dias), as dietas foram fornecidas duas vezes ao dia, às $7 \mathrm{e}$ $16 \mathrm{~h}$, permitindo-se $10 \%$ de sobras. Consta na Tabela $1 \mathrm{a}$ composição das dietas, denominadas de acordo com os ingredientes (milho moído, casca de soja ou farelo de gérmen de milho) avaliados (Tabela 2).

As dietas foram fornecidas na proporção volumoso:concentrado 60:40, segundo recomendações do AFRC (1993), e apresentavam aproximadamente $12,7 \%$ de PB e $66,8 \%$ de NDT na MS, de forma a proporcionar $1,1 \mathrm{~kg}$ de $\mathrm{PV} /$ dia. Os ingredientes dos concentrados foram triturados em moinho com peneira de $3 \mathrm{~mm}$.

Diariamente, antes do primeiro trato, as sobras de alimentos do dia anterior foram recolhidas e pesadas e, a cada dois dias, foram amostradas representativamente. As amostras parciais no dia de coleta foram pré-secas em estufa de circulação e renovação de ar a $55^{\circ} \mathrm{C}$ por 72 horas. Após a secagem, foram novamente amostradas, compondo somente uma amostra semanal por animal, para possibilitar a avaliação do consumo, da conversão e da eficiência alimentar.

Para o ajuste da relação volumoso:concentrado, uma vez por semana retiraram-se aleatoriamente de vários pontos do silo tipo poço amostras de silagem de milho, que foram présecas em estufa de circulação e renovação de ar a $55^{\circ} \mathrm{C}$ por 72 horas e, posteriormente, formaram uma amostra composta.

Os ingredientes e as sobras foram moídos em peneira com crivos de $1 \mathrm{~mm}$, para determinação dos teores de MS, PB $(\mathrm{PB}=\mathrm{N} \times 6,25)$, pelo método de micro-kjeldahl (AOAC, 1995), FDN e FDA (Van Soest, 1967). A digestão foi submetida a controle de temperatura e pressão em autoclave por 60 minutos a $0,5 \mathrm{~atm}$ e $111^{\circ} \mathrm{C}$ (adaptado de Pell \& Schofield, 1992). Nos ingredientes, também foram determinados os teores de MO e EE pelo método Soxhlet (AOAC, 1995). Os teores de amido dos ingredientes foram determinados segundo a metodologia de extração de Hendrix (1993), utilizando-se o ácido dinitrosalicílico (Miller, 1959) para a leitura colorimétrica.

No primeiro dia de adaptação, os animais foram pesados apenas para controle durante esta fase. Após os 21 dias de adaptação às dietas, foram submetidos a jejum alimentar e hídrico (15 horas) e à pesagem para que este peso passasse a ser referência para a avaliação do ganho de peso. O período total de confinamento durou 118 dias, dos quais 97 dias foram utilizados para avaliação do ganho de peso.

Os animais foram abatidos em três etapas, à medida que atingiam $450 \mathrm{~kg}$, em frigorífico comercial, sempre em jejum alimentar e hídrico de 15 horas. Após a obtenção dos pesos de abate e de carcaça quente, calculou-se o rendimento de carcaça dos animais.
Tabela 2 - Participação dos ingredientes (\% MS) e composição bromatológica das dietas experimentais

Table 2 - Ingredient (\%DM) and chemical compositions of diets

\begin{tabular}{|c|c|c|c|}
\hline \multirow[b]{2}{*}{$\begin{array}{l}\text { Ingrediente } \\
\text { Ingredient }\end{array}$} & \multicolumn{3}{|c|}{$\begin{array}{c}\text { Dieta } \\
\text { Diet }\end{array}$} \\
\hline & $\begin{array}{l}\mathrm{MI}^{1} \\
C G^{1}\end{array}$ & $\begin{array}{l}\mathrm{MICS}^{2} \\
\mathrm{CGSSH}^{2}\end{array}$ & $\begin{array}{l}\mathrm{MIFGM}^{3} \\
C G C G M^{3}\end{array}$ \\
\hline $\begin{array}{l}\text { Silagem de milho } \\
\text { Corn silage }\end{array}$ & 60,0 & 60,0 & 60,0 \\
\hline $\begin{array}{l}\text { Milho moído } \\
\text { Ground corn }\end{array}$ & 25,0 & 8,2 & 8,5 \\
\hline $\begin{array}{l}\text { Casca de soja } \\
\text { Soybean seed hulls }\end{array}$ & - & 19,3 & - \\
\hline $\begin{array}{l}\text { Farelo de gérmen de milho } \\
\text { Corn germ meal }\end{array}$ & - & - & 20,0 \\
\hline $\begin{array}{l}\text { Farelo de girassol } \\
\text { Sunflower meal }\end{array}$ & 13,5 & 11,0 & 10,0 \\
\hline $\begin{array}{l}\text { Uréia } \\
\text { Urea }\end{array}$ & 0,8 & 0,8 & 0,8 \\
\hline $\begin{array}{l}\text { Suplemento mineral }{ }^{4} \\
\text { Mineral supplement }\end{array}$ & 0,7 & 0,7 & 0,7 \\
\hline Total & 100,0 & 100,0 & 100,0 \\
\hline & & $\begin{array}{l}\text { omposiç } \\
\text { ompositio }\end{array}$ & \\
\hline $\begin{array}{l}\text { Proteína bruta }(\%) \\
\text { Crude protein (\%) }\end{array}$ & 12,7 & 12,6 & 12,8 \\
\hline $\begin{array}{l}\text { Energia metabolizável } \\
\text { (Mcal/kg MS) } \\
\left.\text { Metabolizable energy (Mcal.kg } D M^{-1}\right)\end{array}$ & 2,4 & 2,4 & 2,4 \\
\hline $\begin{array}{l}\text { Nutriente digestível total }{ }^{5}(\%) \\
\text { Total digestible nutrient } \\
\text { (\%) }\end{array}$ & 67,6 & 66,0 & 66,8 \\
\hline $\begin{array}{l}\text { Fibra em detergente neutro (\%) } \\
\text { Neutral detergent fiber (\%) }\end{array}$ & 30,8 & 42,0 & 32,8 \\
\hline $\begin{array}{l}\text { Fibra em detergente ácido (\%) } \\
\text { Acid detergent fiber (\%) }\end{array}$ & 17,7 & 27,2 & 17,6 \\
\hline
\end{tabular}

${ }^{1} \mathrm{MI}$ : milho moído como fonte energética; ${ }^{2} \mathrm{MICS}$ : casca de soja substituindo $70 \%$ do milho moído nessa dieta; ${ }^{3}$ MIFGM: farelo de gérmen de milho substituindo $70 \%$ do milho moído nessa dieta.

${ }^{1} \mathrm{CG}$ : ground corn as energy source; ${ }^{2} \mathrm{CGSH}$ : soybean hulls replacing $70 \%$ of ground corn in the diet; ${ }^{3}$ CGCGM: corn germ meal replacing $70 \%$ of ground corn in the diet.

${ }^{4}$ Composição $(\mathrm{kg})$ (Composition): $\mathrm{Ca}=100,0 \mathrm{~g} ; \mathrm{P}=50,4 \mathrm{~g} ; \mathrm{Na}=251,9 \mathrm{~g}$; $\mathrm{Cl}=408,5 \mathrm{~g} ; \mathrm{Zn}=5040,0 \mathrm{mg} ; \mathrm{Cu}=2228,7 \mathrm{mg} ; \mathrm{Co}=218,2 \mathrm{mg} ; \mathrm{I}=118,0$ $\mathrm{mg} ; \mathrm{S}=19091,0 \mathrm{mg}$

5 Estimado a partir dos valores de energia metabolizável (Mcal/kg MS) dos ingredientes (Tabela 1).

${ }^{5}$ Estimated by metabolizable energy values (Mcal. $\mathrm{kg} \mathrm{DM}^{-1}$ ) of ingredients (Table 1).

O delineamento experimental utilizado foi o inteiramente casualizado, com sete repetições e três dietas. Os resultados obtidos foram submetidos à análise de variância pelo procedimento GLM do Statistical Analysis Systems (1995), aplicando-se o teste Tukey a 5\% de probabilidade, para comparação das médias.

\section{Resultados e Discussão}

Na Tabela 3 encontram-se as médias de consumo de nutrientes. Foi observada diferença $(\mathrm{P}<0,05)$ no consumo de FDA quando $70 \%$ do milho moído foi substituído por casca de soja. 
Tabela 3 - Consumo de MS, PB, FDN e FDA em novilhos Nelore alimentados com dietas contendo casca de soja ou farelo de gérmen de milho em substituição parcial ao milho moído

Table 3 - Intakes of DM, CP, NDF, and ADF of Nellore steers fed diets with soybean hulls or corn germ meal partially replacing ground corn

\begin{tabular}{|c|c|c|c|c|}
\hline \multirow[b]{2}{*}{$\begin{array}{l}\text { Consumo } \\
\text { Intake }\end{array}$} & \multicolumn{3}{|c|}{$\begin{array}{c}\text { Dieta } \\
\text { Diet }\end{array}$} & \multirow[b]{2}{*}{$\mathrm{CV}^{5}$} \\
\hline & $\begin{array}{l}\mathrm{MI}^{1} \\
C G^{1}\end{array}$ & $\begin{array}{l}\mathrm{MICS}^{2} \\
\mathrm{CGSH}^{2}\end{array}$ & $\begin{array}{l}\mathrm{MIFGM}^{3} \\
C G C G M^{3}\end{array}$ & \\
\hline Matéria seca, kg/dia (Dry matter, kg.day ${ }^{-1}$ ) & 10,78 & 9,73 & 10,62 & 17,28 \\
\hline Matéria seca, \% $\mathrm{PV}^{4}$ (Dry matter, \%BW) & 2,65 & 2,43 & 2,58 & 16,45 \\
\hline Proteína bruta, kg/dia (Crude protein, $\mathrm{kg}$ day $^{-1}$ ) & 1,40 & 1,22 & 1,41 & 16,91 \\
\hline Fibra em detergente neutro, $\mathrm{kg}$ /dia (Neutral detergent fiber, $\mathrm{kg}^{\text {day }}{ }^{-1}$ ) & 3,41 & 3,89 & 3,60 & 17,98 \\
\hline Fibra em detergente neutro, \% $\mathrm{PV}^{4}$ (Neutral detergent fiber, \%BW) & 0,84 & 0,97 & 0,87 & 17,75 \\
\hline Fibra em detergente ácido, $\mathrm{kg} /$ dia (Acid detergente fiber, $\mathrm{kg}^{\text {day }} \mathrm{y}^{-1}$ ) & $2,29 \mathrm{~b}$ & $2,85 \mathrm{a}$ & $2,27 \mathrm{~b}$ & 17,93 \\
\hline Fibra em detergente ácido, $\% \mathrm{PV}^{4}$ (Acid detergente fiber, $\% B W$ ) & $0,56 \mathrm{~b}$ & $0,71 \mathrm{a}$ & $0,55 b$ & 16,62 \\
\hline
\end{tabular}

Médias seguidas de letras distintas, na mesma linha, diferem $(P<0,05)$ pelo teste Tukey.

Means followed by different letter in the same row differ $(P>0.05)$ by Tukey test.

${ }^{1} \mathrm{MI}$ : milho moído como fonte energética; ${ }^{2} \mathrm{MICS}$ : casca de soja em substituição a $70 \%$ do milho moído; ${ }^{3} \mathrm{MIFGM:} \mathrm{farelo} \mathrm{de} \mathrm{gérmen} \mathrm{de} \mathrm{milho} \mathrm{em} \mathrm{substituição}$ a $70 \%$ do milho moído.

${ }^{1} \mathrm{CG}$ : ground corn as energy source; ${ }^{2} \mathrm{CGSH}$ : soybean hulls replacing $70 \%$ of ground corn in the diet; ${ }^{3} \mathrm{CGCGM}$ : corn germ meal replacing $70 \%$ of ground corn in the diet.

${ }^{4} \mathrm{PV}=$ Peso vivo (BW = body weight).

$5 \mathrm{CV}=$ Coeficiente de variação (\%) (coefficient of variation \%).

As fontes energéticas não influenciaram $(\mathrm{P}>0,05) \mathrm{o}$ consumo de MS, mesmo quando em $\% \mathrm{PV}$, o que está de acordo com os resultados obtidos por Thiago et al. (2000), que avaliaram níveis $(0 ; 33 ; 67$ e $100 \%)$ de substituição do milho pela casca de soja e não observaram efeito significativo sobre o consumo de MS, com média de $2,4 \%$ do PV, em novilhos Nelore em confinamento, alimentados com silagem de sorgo.

Mendes et al. (2005) substituíram 58\% do milho moído por casca de soja e farelo de gérmen de milho, utilizando silagem de milho como volumoso, em dietas para novilhos cruzados em confinamento e obtiveram resultado médio para consumo de matéria seca de $2,53 \%$ do PV, muito semelhante ao encontrado neste trabalho (2,58\% do PV).

Não se observou diferença significativa para o consumo de FDN. Embora não significativo, o consumo na dieta contendo casca de soja foi 13,40 e $10,31 \%$ mais elevado que o das dietas com milho moído e farelo de gérmen de milho, respectivamente. O consumo de MS está diretamente relacionado ao conteúdo de FDN do alimento e das dietas, pois a fermentação e a passagem dessa fração pelo retículo-rúmen são mais lentas que as de outros constituintes dietéticos, apresentando grande efeito no enchimento e no tempo de permanência (Van Soest, 1994). O consumo de MS proporcionado pela dieta contendo casca de soja foi 10,8 e $9,1 \%$ menor que o das dietas contendo milho moído e farelo de gérmen de milho, respectivamente, sugerindo que a FDN possivelmente tenha participado na regulação física do consumo na dieta com casca de soja.

Os consumos deFDN obtidos nesse trabalho ( $3,63 \mathrm{~kg} / \mathrm{dia})$ foram inferiores aos observados por Mendes et al. (2005), em novilhos mestiços 3/4 Simental x 1/4 Nelore, com 391,3 kg de peso médio inicial, alimentados com milho como fonte energética $(5,43 \mathrm{~kg} / \mathrm{dia})$ ou casca de soja em substituição ao milho $(5,60 \mathrm{~kg} / \mathrm{dia})$. Esses autores obtiveram elevados consumos de MS (10,75 e 10,55 kg/animal/dia) e atribuíramnos à contribuição do farelo de girassol, visto que aproximadamente $20 \%$ da FDN presente nas dietas era proveniente deste ingrediente protéico, caracterizado por apresentar fibra de baixa degradabilidade ruminal (Galati, 2004).

Houve efeito significativo $(\mathrm{P}<0,05)$ no consumo de FDA com maiores valores para a dieta contendo casca de soja $(2,85 \mathrm{~kg} / \mathrm{dia})$ em relação às demais $(2,28 \mathrm{~kg} / \mathrm{dia})$. Essa diferença possivelmente seja resultado do menor consumo de matéria seca na dieta contendo casca de soja $(9,73 \mathrm{vs}$ $10,78$ e $10,62 \mathrm{~kg} / \mathrm{dia})$. Considerando-se os tempos de permanência do milho moído (15,6 horas), da casca de soja (15,5 horas) e do farelo de gérmen de milho (19,9 horas) no retículo-rúmen (Mendes et al., 2006), parte dos consumos poderia ser atribuída à baixa digestibilidade ruminal da FDA da casca de soja (20,5\%), em razão de seu tempo de permanência em relação ao do milho moído $(38,5 \%)$ e do farelo de gérmen de milho $(42,9 \%)$ (Galati, 2004). Outra explicação seria o fato de que a dieta com casca de soja apresentaria em sua composição aproximadamente $54 \%$ a mais de FDA que a dieta com milho moído e farelo de gérmen de milho. O teor de FDN na dieta contendo casca de soja seria 36,4 e $28,0 \%$ mais elevado que nas dietas com milho moído e farelo de gérmen de milho, o que, associado às baixas digestibilidades ruminais tanto da FDN (28,3\%) quanto da FDA da casca de soja, poderia influenciar o consumo. Embora Mendes et al. (2005) tenham obtido maior ingestão de FDA para a dieta contendo casca de soja $(2,95$ vs $2,59 \mathrm{~kg} / \mathrm{animal} / \mathrm{dia})$, não foi observado efeito sobre o consumo de MS (10,55 vs 10,75 kg/animal/dia), comparativamente ao milho moído. 
Os consumos de PB não apresentaram diferença significativa entre dietas, mas observou-se que os animais que receberam dieta com casca de soja consumiram $185 \mathrm{~g}(13,17 \%)$ a menos que aqueles alimentados com as dietas com milho e farelo de gérmen de milho $(1,4 \mathrm{e} 1,41 \mathrm{~kg}$ de $\mathrm{PB} / \mathrm{dia})$, o que pode ser explicado pelo menor consumo de matéria seca (10,8\%). Apesar disso, não houve diminuição significativa no ganho de peso, que foi apenas $4,6 \%$ menor que o obtido na dieta contendo milho moído. Mendes et al. (2005) observou que a ingestão de PB da dieta contendo milho moído foi $110 \mathrm{~g}$ maior $(\mathrm{P}<0,01)$ que a da dieta contendo farelo de gérmen de milho, provavelmente em razão da granulometria do farelo de gérmen de milho, que, embora seja comercializado peletizado, possui partículas muito pequenas que se aderem à fibra da silagem, aumentando a porcentagem de PB nas sobras. No entanto, considerando-se os valores observados neste experimento, o fato descrito por Mendes et al. (2005) não ocorreu. Na dieta com farelo de gérmen de milho, os consumos de MS e PB foram de 10,62 e 1,41 kg/dia, respectivamente, que correspondem a uma dieta com $13,3 \%$ de PB. Para a dieta contendo milho moído, o consumo foi de 13,0\% de PB, enquanto, para aquela contendo casca de soja, esse valor foi de $12,5 \%$, sugerindo que o consumo de PB na dieta contendo casca de soja tenha sido inferior em decorrência de uma possível limitação física provocada pelo consumo de fibra.

As médias dos pesos de adaptação, dos pesos ao início e ao final do período experimental, do ganho de peso e da conversão alimentar são apresentadas na Tabela 4.

Calculando o ganho de peso durante a adaptação, observou-se menor ganho de peso para a dieta contendo milho moído ( $0,8 \mathrm{~kg} / \mathrm{dia})$, enquanto, nas dietas com casca de soja e farelo de gérmen de milho, esses ganhos foram de 1,1 e $1,2 \mathrm{~kg} / \mathrm{dia}$, respectivamente.

O desenvolvimento da flora microbiana e a cinética ruminal variam de acordo com o tipo e a quantidade de grãos ou co-produtos utilizados nas formulações. Para isso, no período de adaptação, o principal objetivo é amenizar as mudanças no ambiente ruminal com a transição de uma dieta exclusivamente forrageira para outra contendo alimentos concentrados. Os resultados encontrados neste trabalho indicam melhor adaptação dos animais, no período de 21 dias, às dietas contendo casca de soja e farelo de gérmen de milho, o que pode estar relacionado ao melhor balanço entre nutrientes, principalmente amido:proteína (Galati, 2004). Quando introduzidos casca de soja e farelo de gérmen de milho em substituição parcial ao milho moído, pode haver influência positiva sobre o ecossistema ruminal (Mendes et al., 2006). Experimentos anteriores comprovaram que a suplementação de bovinos com casca de soja provocou efeito negativo sobre a digestão da fibra menor que a suplementação com milho (Anderson et al., 1988; Grigsby et al., 1993).

A observação dos dados sugere que, no caso de dietas contendo altos teores de amido proveniente do milho, o período de adaptação deve ser maior que quando se utilizam dietas com menores quantidades de amido e maiores teores de FDN de boa qualidade. Galati et al. (2002), ao utilizarem casca de soja e farelo de gérmen de milho em substituição a $58 \%$ do milho, não observaram diferenças nos valores de $\mathrm{pH}$ ruminal quando o milho compôs $18,9 \%$ da dieta, de modo que o menor valor correspondeu a 6,5 nessa dieta. Da mesma forma, Galati (2004) utilizou dietas semelhantes às desse trabalho e observou que naquela contendo $25 \%$ de

Tabela 4 - Pesos de adaptação, inicial, final $(\mathrm{kg})$, peso de abate $(\mathrm{kg})$, ganho de peso (kg/dia), conversão alimentar ( $\mathrm{kg}$ de MS ingerida/kg de ganho) e eficiência alimentar ( $\mathrm{kg}$ ganho/kg MS ingerida) de novilhos Nelore alimentados com casca de soja ou farelo de gérmen de milho em substituição parcial ao milho moído

Table 4 - Adaptation, initial, and final weights $(\mathrm{kg})$, slaughter weight $(\mathrm{kg})$, weight gain ( $\left.\mathrm{kg}^{\text {day }}{ }^{-1}\right)$, feed:gain ratio ( $\mathrm{kg}_{\text {of }} \mathrm{DM}$ intake. $\mathrm{kg}$ of gain $\left.{ }^{-1}\right)$ and feed efficiency ( $\mathrm{kg}$ of gain. $\mathrm{kg}$ of DM intake $\mathrm{e}^{-1}$ ) of Nellore steers fed diets with soybean hulls or corn germ meal partially replacing ground corn

\begin{tabular}{|c|c|c|c|c|}
\hline \multirow[b]{2}{*}{$\begin{array}{l}\text { Variável } \\
\text { Variable }\end{array}$} & \multicolumn{3}{|c|}{$\begin{array}{c}\text { Dieta } \\
\text { Diet }\end{array}$} & \multirow[b]{2}{*}{$\mathrm{CV}^{4}$} \\
\hline & $\begin{array}{l}\mathrm{MI}^{1} \\
C G^{1}\end{array}$ & $\begin{array}{l}\mathrm{MICS}^{2} \\
\mathrm{CGSH}^{2}\end{array}$ & $\begin{array}{c}\text { MIFGM }^{3} \\
C G C G M^{3} \\
\end{array}$ & \\
\hline Peso de adaptação (Adaptation weight) & 326,16 & 315,89 & 321,61 & 4,22 \\
\hline Peso inicial (Initial weight) & 342,94 & 339,80 & 347,14 & 5,43 \\
\hline Peso de abate (Slaughter weight) & 468,57 & 456,99 & 476,87 & 4,14 \\
\hline Ganho de peso (Weight gain) & 1,35 & 1,29 & 1,32 & 15,33 \\
\hline Conversão alimentar (Feed:gain ratio) & 8,00 & 7,54 & 8,04 & 12,31 \\
\hline Eficiência alimentar (Feed efficiency) & 0,12 & 0,13 & 0,12 & 14,20 \\
\hline
\end{tabular}

Médias seguidas de letras distintas, na mesma linha, diferem $(P<0,05)$ pelo teste Tukey.

Means followed by different letter in the same row differ $(P>0.05)$ by Tukey test.

${ }^{1} \mathrm{MI}$ : milho moído como fonte energética; ${ }^{2} \mathrm{MICS}$ : casca de soja em substituição a $70 \%$ do milho moído; ${ }^{3} \mathrm{MIFGM:} \mathrm{farelo} \mathrm{de} \mathrm{gérmen} \mathrm{de} \mathrm{milho} \mathrm{em} \mathrm{substituição}$ a $70 \%$ do milho moído.

1 CG: ground corn as energy source; ${ }^{2} \mathrm{CGSH}$ : soybean hulls replacing $70 \%$ of ground corn in the diet; ${ }^{3}$ CGCGM: corn germ meal replacing $70 \%$ of ground corn in the diet.

${ }^{4} \mathrm{CV}=$ Coeficiente de variação (\%) (coefficient of variation \%). 
milho o menor valor de $\mathrm{pH}$ ruminal foi de 6,5 , sugerindo que, embora o pH ruminal não se altere drasticamente quando a introdução de milho corresponde a até $25 \%$ da dieta, a estabilidade ruminal pode ser afetada nos primeiros dias de fornecimento dos alimentos, com suposta redução na atividade microbiana, mesmo que não haja reflexos sobre o consumo. Segundo Johnson \& Boyles (1991), em dietas para o período inicial de confinamento de bovinos, é ideal utilizar grãos ou co-produtos com alto conteúdo de casca e fibra, facilitando a adaptação dos animais ao consumo de grãos.

Com a introdução de casca de soja ou farelo de gérmen de milho em substituição parcial ao milho moído, não foi observada diferença significativa sobre o desempenho, embora, para as dietas com farelo de gérmen de milho e casca de soja, tenham sido observados ganhos 2,3 e 4,6\% inferiores ao milho moído. Mendes et al. (2005) substituíram 58\% do milho pelos mesmos ingredientes testados (casca de soja e farelo de gérmen de milho) em dietas para novilhos mestiços em confinamento e verificaram médias dos ganhos diários de peso $(1,15 \mathrm{~kg} / \mathrm{dia})$ e conversões alimentares inferiores $(9,2 \mathrm{~kg}$ MS ingerida/ $\mathrm{kg}$ de ganho) às deste experimento. Os autores ressaltaram que, embora não tenha havido diferença estatística, o ganho proporcionado pela dieta contendo farelo de gérmen de milho foi numericamente $(7,7 \%)$ mais elevado que o observado nas dietas contendo milho moído ou casca de soja.

A partir dos valores de energia metabolizável (Tabela 1) e da participação de cada ingrediente nas dietas (Tabela 2), estimaram-se os fornecimentos de 26,35;22,77 e25,67 Mcal/dia para as dietas contendo milho moído, casca de soja e farelo de gérmen de milho, respectivamente. Quando comparados esses valores médios de EM aos de ganhos de peso diários $(1,35 ; 1,29$ e 1,32 kg/dia, para MI, MICS e MIFGM, respectivamente), nota-se discordância da relação direta entre maior consumo de energia e maiores ganhos. A dieta contendo casca de soja continha, em média, 14,2\% menos EM que as demais. No entanto, proporcionou somente $3,5 \%$ a menos de ganho médio diário. A casca de soja pode proporcionar melhor estabilidade ruminal, determinando economia energética no rúmen, expressando ganhos semelhantes às dietas contendo exclusivamente milho moído ou farelo de gérmen de milho substituindo parcialmente o milho moído, apesar do menor fornecimento de energia metabolizável.

Não houve diferença $(\mathrm{P}>0,05)$ para os valores de conversão (CA) ou de eficiência alimentar (EA) na dieta com casca de soja, que, apresentou numericamente os melhores valores de CA e EA (7,54 kg de MS ingerida/ $\mathrm{kg}$ de ganho e $13,26 \mathrm{~kg}$ de ganho/ $\mathrm{kg}$ MS ingerida). Considerando os menores consumos de matéria seca $(10,0 \%)$ e proteína bruta $(15,16 \%)$, os maiores consumos tanto de FDN (acima de 28\%) quanto de FDA (aproximadamente $54 \%)$ e a pequena diferença no ganho (3,5\% em média), verifica-se que a dieta contendo casca de soja foi a mais eficiente. Resultados semelhantes foram obtidos por Fisher \& Mühlbach (1999), ao avaliarem, em novilhas, o efeito da substituição do grão de milho ou de sorgo pela casca de soja em diferentes níveis $(0,25,50$ e $75 \%)$. Os autores registraram CA de $7,74 \mathrm{~kg} \mathrm{MS}$ ingerida/ $\mathrm{kg}$ ganho, ganhos de $1,17 \mathrm{~kg} / \mathrm{dia}$ e EA superior ( $0,15 \mathrm{~kg}$ ganho/ $\mathrm{kg}$ MS ingerida). Independentemente dos resultados proporcionados pelas diferentes dietas e pela categoria animal, é evidente o potencial da casca de soja para utilização na alimentação de bovinos.

$\mathrm{Na}$ Tabela 5 constam os pesos de carcaça quente e os rendimentos de carcaça, seguidos pelos coeficientes de variação (\%).

Os rendimentos de carcaça não foram influenciados $(\mathrm{P}>0,05)$ pela inclusão da casca de soja ou do farelo de gérmen de milho em substituição parcial ao milho moído, observando-se valor médio de $54,52 \%$, que se encontra na faixa de rendimento de 53 a $59 \%$, normalmente obtida para bovinos da raça Nelore (Ferreira et al., 1999; Jorge et al., 1999).

Segundo Prado et al. (2000) e Galati et al. (2004), o rendimento de carcaça, além dos fatores de oscilação inerentes ao

Tabela 5 - Peso de carcaça quente $(\mathrm{kg})$ e rendimento de carcaça (\%) de novilhos Nelore alimentados com dietas contendo casca de soja ou farelo de gérmen de milho em substituição parcial ao milho moído

Table 5 - Hot carcass weight (kg) and carcass dressing (\%) of Nellore steers fed diets with soybean hulls or corn germ meal partially replacing ground corn

\begin{tabular}{|c|c|c|c|c|}
\hline \multirow[b]{2}{*}{$\begin{array}{l}\text { Variável } \\
\text { Variable }\end{array}$} & \multicolumn{3}{|c|}{$\begin{array}{c}\text { Dieta } \\
\text { Diet }\end{array}$} & \multirow[b]{2}{*}{$\mathrm{CV}^{4}$} \\
\hline & $\begin{array}{l}\mathrm{MI}^{1} \\
C G^{1}\end{array}$ & $\begin{array}{l}\mathrm{MICS}^{2} \\
\mathrm{CGSH}^{2}\end{array}$ & $\begin{array}{l}\mathrm{MIFGM}^{3} \\
C G C G M^{3}\end{array}$ & \\
\hline Peso carcaça quente (Hot carcass weight) & 255,43 & 248,43 & 259,64 & 5,24 \\
\hline Rendimento de carcaça (Carcass dressing) & 54,68 & 54,52 & 54,35 & 6,58 \\
\hline
\end{tabular}

Médias seguidas de letras distintas, na mesma linha, diferem $(P<0,05)$ pelo teste Tukey.

Means followed by different letter in the same row differ $(P>0.05)$ by Tukey test.

${ }^{1} \mathrm{MI}$ : milho moído como fonte energética; ${ }^{2}$ MICS: casca de soja em substituição a $70 \%$ do milho moído; ${ }^{3}$ MIFGM: farelo de gérmen de milho em substituição a $70 \%$ do milho moído.

1 CG: ground corn as energy source; ${ }^{2} \mathrm{CGSH}$ : soybean hulls replacing $70 \%$ of ground corn in the diet; ${ }^{3}$ CGCGM: corn germ meal replacing $70 \%$ of ground corn in the diet.

${ }^{4} \mathrm{CV}=$ Coeficiente de variação (\%) (coefficient of variation \%). 
animal (genótipo, enchimento do rúmen, período de jejum e transporte), pode sofrer influência do local de abate, em decorrência do maior ou do menor grau de rigidez no processo de limpeza das carcaças.

\section{Conclusões}

A substituição de $70 \%$ do milho moído por casca de soja ou farelo de gérmen de milho não afetou o consumo de matéria seca, o ganho de peso, a conversão e eficiência alimentar e o rendimento de carcaça de novilhos Nelore confinados.

A inclusão desses co-produtos em substituição parcial ao milho da dieta para animais em confinamentos pode ser feita em até $70 \%$. Assim, a escolha entre esses ingredientes deve ser feita com base na análise econômica, considerando a disponibilidade na região.

\section{Literatura Citada}

AGRICULTURAL AND FOOD RESEARCH COUNCIL - AFRC. Energy and protein requirements of ruminants. Wallington: CAB International, 1993. 159p.

ANDERSON, S.W.; MERRIL, J.K.; KLOPFENSTEIN, T.J. Soybean hulls as energy supplement for grazing ruminant. Journal of Animal Science, v.66, n.11, p.2959-2964, 1988.

ASSOCIATION OF OFFICIAL ANALYTICAL CHEMISTRY AOAC. Official methods of analysis. 16.ed. Arlington: Patricial Cunnif, 1995. 1025p.

EZEQUIEL, J.M.B.; GALATI, R.L.; MENDES, A.R. et al. Desempenho e características de carcaça de bovinos da raça Nelore alimentados com diferentes fontes energéticas, em confinamento. In: REUNIÃO ANUAL DA SOCIEDADE BRASILEIRA DE ZOOTECNIA, 41., 2004, Campo Grande. Anais... Campo Grande: Sociedade Brasileira de Zootecnia, 2004 (CD-ROM). Nutrição de Ruminantes 251.

FERREIRA, M.A.; VALADARES FILHO, S.C.; COELHO DA SILVA, J.F. et al. Consumo, conversão alimentar, ganho de peso e características da carcaça de bovinos F1 Simental x Nelore. Revista Brasileira de Zootecnia, v.28, n.2, p.343-351, 1999.

FISCHER, V.; MÜHLBACH, O.R.F. Substituição do grão de milho por casca de soja no desempenho de novilhas de corte confinadas. Pesquisa Agropecuária Gaúcha, v.5, n.1, p.143$148,1999$.

GALATI, R.L.; EZEQUIEL, J.M.B.; MENDES, A.R. et al. Influência de diferentes fontes energéticas sobre os valores de $\mathrm{pH}$ e concentrações ruminais de nitrogênio amoniacal no rúmen e no intestino. In: REUNIÃO ANUAL DA SOCIEDADE BRASILEIRA DE ZOOTECNIA, 39., 2002, Recife. Anais... Recife: Sociedade Brasileira de Zootecnia, 2002 (CD-ROM) Nutrição de Ruminantes 06sbz1479.

GALATI, R.L.; EZEQUIEL, J.M.B.; SILVA, O.G.C. et al. Desempenho e características da carcaça de novilhos Nelore alimentados com dietas contendo casca de soja ou farelo de gérmen de milho substituindo parcialmente o milho. In: REUNIÃO ANUAL DA SOCIEDADE BRASILEIRA DE ZOOTECNIA, 40., 2003, Santa Maria. Anais... Santa Maria: Sociedade Brasileira de Zootecnia, 2003. (CD-ROM) Nutrição de Ruminantes 6_05041_2_laisgalati.

GALATI, R.L. Co-produtos do milho, soja e girassol em dietas para bovinos de corte. Jaboticabal: Universidade Estadual Paulista, 2004. 168p. Tese (Doutorado em Zootecnia) Universidade Estadual Paulista, 2004.
GRIGSBY, K.N.; KERLEY, M.S.; PATERSON, J.A. et al. Combinations of starch and digestible fiber in supplements for steers consuming a low-quality bromegrass hay diet. Journal of Animal Science, v.71, n.4, p.1057-64, 1993.

HENDRIX, D.L. Rapid extraction and analysis of nonstructural carbohydrates in plant tissues. Crop Science, v.33, n.6, p.1306 $-1311,1993$.

HOOVER, W.H. Chemical factors involved in ruminal fiber digestion. Journal of Dairy Science, v.69, n.10, p.2755-2766, 1986.

JOHNSON, L.; BOYLES, S. Oats as a feed for beef cattle. NDSU Extension Service. Extension Bulletin, AS-1020. North Dakota State University, 1991.

JORGE, A.M.; FONTES, C.A.A.; PAULINO, M.F. et al. Desempenho produtivo de quatro raças zebuínas, abatidos em três estádios de maturidade. 2. Características da carcaça. Revista Brasileira de Zootecnia, v.28, n.2, p.381-387, 1999.

MENDES, A.R.; EZEQUIEL, J.M.B.; GALATI, R.L. et al. Desempenho, parâmetros plasmáticos e características de carcaça de novilhos alimentados com farelo de girassol e diferentes fontes energéticas, em confinamento. Revista Brasileira de Zootecnia, v.34, n.2, p.324-364, 2005.

MENDES, A.R.; EZEQUIEL, J.M.B.; GALATI, R.L. et al. Cinética digestiva e eficiência de síntese de proteína microbiana em novilhos alimentados com farelo de girassol e diferentes fontes energéticas. Revista Brasileira de Zootecnia, v.35, n.1, p.264-274, 2006.

MILLER, G.L. Use of dinitrosalicylic acid reagent for determination of reducing sugar. Analytical Chemistry, v.31, n.3, p.426$428,1959$.

PELL, A.N.; SCHOFIELD, P. Computerized monitoring of gas production to measure forage digestion in vitro. Journal of Dairy Science, v.76, n.4, p.1063-1073, 1992.

PRADO, I.N.; PINHEIRO, A.D.; ALCALDE, C.R. et al. Níveis de substituição do milho pela polpa cítrica peletizada sobre o desempenho e características de carcaça de bovinos mestiços confinados. Revista Brasileira de Zootecnia, v.29, n.7, p.2135-2141, 2000 .

SILVA, L.D.F.; EZEQUIEL, J.M.B.; AZEVEDO, P.S. et al. Digestão total e parcial de alguns componentes de dietas contendo diferentes níveis de casca de soja e fontes de nitrogênio, em bovinos. Revista Brasileira de Zootecnia, v.31, n.3, p.125868, 2002 .

SNIFFEN, C.J.; O'CONNOR, J.D.; Van SOEST, P.J. et al. A net carbohydrate and protein system for evaluating cattle diets: II. Carbohydrate and protein availability. Journal of Animal Science, v.70, n.11, p.3562-3577, 1992.

STATISTICAL ANALYSIS SISTEMS - SAS. Language Guide. v.6. 3.ed. Cary: 1995. 530p.

THIAGO, R.L.S.; SILVA, J.M.; FEIJÓ, G.L.D. et al. Substituição do milho pelo sorgo ou casca de soja em dietas para engorda de bovinos em confinamento. In: REUNIÃO ANUAL DA SOCIEDADE BRASILEIRA DE ZOOTECNIA, 37., 2000, Viçosa, MG. Anais... Viçosa, MG: Sociedade Brasileira de Zootecnia, 2000 (CD-ROM) Nutrição de Ruminantes 0819.

Van SOEST, P. J. Development of a comprehensive system of feed analysis and its applications to forage. Journal of Animal Science, v.26, n.1, p.119-28, 1967.

Van SOEST, P.J. Nutritional ecology of the ruminant. 2.ed. New York: Ithaca, 1994. 476p.

WATANABE, P.H. Adequacidade de indicadores internos na avaliação da digestibilidade de dietas contendo co-produtos do milho, soja e girassol. Jaboticabal: Universidade Estadual Paulista, 2004. 51p. Monografia (Graduação em Zootecnia) Universidade Estadual Paulista, 2004. 